Dear Author,

Please, note that changes made to the HTML content will be added to the article before publication, but are not reflected in this PDF.

Note also that this file should not be used for submitting corrections. 


\title{
A combined assessment of air and noise pollution on the High Line, New York City
}

\author{
E.A. King ${ }^{a, *}$, E.P. Bourdeau ${ }^{a}$, X.Y.K. Zheng ${ }^{a}$, F. Pilla ${ }^{b}$ \\ ${ }^{a}$ Acoustics Program and Lab, Department of Mechanical Engineering, University of Hartford, USA \\ ${ }^{\mathrm{b}}$ Department of Civil, Structural \&' Environmental Engineering, Trinity College Dublin, Ireland
}

\section{A R T I C L E I N F O}

\section{Article history:}

Available online $\mathrm{xxxx}$

\section{Keywords:}

Pedestrian exposure

Urban planning and design

Particulate matter

Environmental noise

\begin{abstract}
A B S T R A C T
The High Line is an elevated public park in New York City, transformed from an unused freight rail line. Pedestrians walking through Manhattan's West Side can walk either on the High Line or on a footpath below. Using Manhattan as a laboratory, this paper offers a combined assessment of noise and particulate matter pollution for its pedestrians. Noise and $\mathrm{PM}_{2.5}$ levels were recorded simultaneously for two cases (i) pedestrians walking on a footpath alongside road traffic and (ii) pedestrians walking on the elevated High Line. Testing took places over three days in autumn 2014. Results were analysed to investigate if pedestrians using the High Line would have a lower pollution exposure to those using the footpath below. Results showed statistically significant differences between the upper and lower levels in exposure to both pollution types. In order to quantify the overall impact, results are expressed through a combined air-noise pollution index. This index indicates that the average reduction in $\mathrm{PM}_{2.5}$ and noise pollution along the High Line compared to the footpath below is approximately $37 \%$.
\end{abstract}

(c) 2015 Elsevier Ltd. All rights reserved.

\section{Introduction}

Over the last half century the world has experienced rapid urbanisation. For the first time in our history, more than half of the world's population (54\%) now reside in urban areas (United Nations, 2014). Urban areas are typically characterised by high levels of exposure to environmental stressors, with noise and air pollution being the two most dominant. With continued growth and redevelopment within cities, urban planners are now responsible for designing cities that better mitigate noise and air pollution to promote healthier environments.

Environmental noise, often identified as a forgotten pollutant, is now recognised as an environmental and public health issue that needs to be addressed in modern society. Clear links between adverse health effects and noise exposure have been identified, and estimates of their proliferation across the population have been established (Murphy and King, 2014). Excessive exposure to environmental noise can induce annoyance, cause disruption of sleep cycles, lead to cardiovascular disorders and may even impair the cognitive development of children. Noise levels of 65-70 dB(A) outdoors have been considered as a relevant threshold of adverse health effects of noise (Babisch et al., 2005). In the U.S., a 1981 EPA study estimated that over 100 million people (nearly half of the U.S. population) were exposed to road traffic noise levels that may be harmful to health (Hammer et al., 2014). The economic impacts are also significant. The Federal Highways Association reported that, as

* Corresponding author at: Acoustics Program and Lab, Department of Mechanical Engineering, University of Hartford, 200 Bloomfield Avenue, West Hartford, CT 06117, USA. Tel.: +1 8607685953.

E-mail address: eoking@hartford.edu (E.A. King). 
of the end of 2004, more than 2000 miles of noise barriers had been constructed in 45 states and the Commonwealth of Puerto Rico at a cost of more than $\$ 2.6$ billion ( $\$ 3.4$ billion in 2004 dollars) (Committee on Technology for a Quieter America, 2010). More recently, Swinburn et al. (2015) estimated that a $5 \mathrm{~dB}(\mathrm{~A})$ reduction in exposure levels across the U. S. would reduce the prevalence of hypertension by $1.4 \%$ and coronary heart disease by $1.8 \%$, yielding an annual economic benefit of $\$ 3.9$ billion.

In New York City, noise is consistently reported as the number one quality of life issue affecting residents. In 2012 authorities there recorded over 35,000 noise complaints (City of New York, 2013). In midtown Manhattan average sound pressure levels of 70-85 dB(A) are common (NYC Dept. of Environmental Protection, 2014), levels which pose potential health hazards. To address the issue of environmental noise in New York City, a 30 year old noise code was revised in 2005. Then Mayor Michael Bloomberg commented that the new legislation established "a flexible, yet enforceable noise code that responds to the need for peace and quiet while maintaining New York's reputation as the City that never sleeps" (Skylar and Barowitz, 2005). Along with enforceable legislation, traffic management measures have the potential to significantly reduce levels of noise exposure in an urban environment (King et al., 2011).

In parallel, particulate air pollution is consistently and independently related to serious health effects (Cohen et al., 2005). Particulate matter (PM), fine particles that can penetrate deep into the lungs, have proven adverse effects on the respiratory and cardiovascular systems (Gordon and Reibman, 2000; Dockery, 2011; Pilla, 2014). Particulate matter consists of a combination of organic and inorganic substances including un-combusted fuel, dust and metal fragments and represents a hazardous by-product of the combustion process (Schwela and Zali, 1999). The World Health Organization WHO estimated in 2005 that $\mathrm{PM}_{2.5}$ caused about $3 \%$ of mortality from cardiopulmonary disease, about $5 \%$ of mortality from cancer of the trachea, bronchus, and lung, and about $1 \%$ of mortality from acute respiratory infections in children under 5 years, worldwide (Cohen et al., 2005). Short-term exposure at elevated concentrations can significantly contribute to heart disease; Nawrot et al. (2011) found that traffic exhaust is the single most serious preventable cause of heart attack in the general public, the cause of $7.4 \%$ of all attacks. The National Institute of Environmental Health Sciences conducted a multicity time-series study regarding the acute effect of $\mathrm{PM}_{2.5}$ and PM coarse on the increased risk of death for all causes, including cardiovascular disease, myocardial infarction, stroke, and respiratory mortality for the years 1999-2005. The results showed an increased risk of mortality for all and specific causes associated with $\mathrm{PM}_{2.5}$, and the risks are higher than what was previously observed for $\mathrm{PM}_{10}$ (Zanobetti and Schwartz, 2009).

In New York City, the Department of Health has estimated that fine particle pollution is the cause of more than 2000 deaths annually, 1500 hospital admissions for lung and heart conditions, and 5000 emergency department admissions for asthma between 2009 and 2011 (New York City Department of Health and Mental Hygiene, 2013). In 2008 the EPA estimated that New York City has the most local emissions per square mile of $\mathrm{PM}_{2.5}$ of any large U.S. city - making it an ideal test case for the current study (New York City Department of Health and Mental Hygiene, 2013). In New York, the Department of Health established the New York City Community Air Survey (NYCCAS) to monitor air quality across the city. This involves the measurement of air pollutants on an ongoing basis at 150 locations across the city. The annual average PM $_{2.5}$ level across all NYCCAS sampling sites, adjusting for differences in weather, has been recorded at $11.3 \mu \mathrm{g} / \mathrm{m}^{3}$ at street level, with concentrations varying from less than $9 \mu \mathrm{g} / \mathrm{m}^{3}$ to almost $20 \mu \mathrm{g} / \mathrm{m}^{3}$ across sites throughout the city (New York City Department of Health and Mental Hygiene, 2011). However, these results should be interpreted with some caution. After a literature synthesis for $\mathrm{PM}_{2.5}$ studies in New York City, Levy and Hanna (2011) emphasise that drawing conclusions about the degree of temporal and spatial variability of $\mathrm{PM}_{2.5}$ is complicated by a number of factors, including the influence of averaging time, spatial density of measurements or model outputs, characterisation of background, and statistical criteria employed.

Air pollution may also affect athletes exercising in an urban environment. Air pollution intake during exercise is heightened in comparison to intake during rest due to higher ventilator rates in both nasal and oral breathing (Pierson et al., 1986). Sharman et al. (2004) report that people exercising in environments pervaded by air contaminants are probably at an increased risk due to an exercise-induced amplification in respiratory uptake, lung deposition and toxicity of inhaled pollutants. Recently, the issue of urban air quality for athletes competing in the Beijing International Marathon received international media attention (Stableford, 2014). It was reported that many marathon participants decided not to run the race or chose to wear facemasks to protect themselves from the smog that consisted of high PM concentration.

In urban areas, pedestrians are simultaneously exposed to both noise and air pollutants. Traditionally, noise and air pollution are assessed separately, however, several combined approaches have been explored in recent years (Boogaard et al., 2009; Allen et al., 2009; King et al., 2009; Fung and Lee, 2011; Vlachokostas et al., 2012; Ross et al., 2012; Silva and Mendes, 2012). An integrated assessment becomes necessary because air and noise pollution not only often share a common source, but individuals are exposed to these pollutants simultaneously (Vlachokostas et al., 2014). King et al. (2009) developed a combined air-noise pollution index to assess the effectiveness of a segregated boardwalk in Dublin's city centre in Ireland. This was one of the first assessments to consider noise and air pollution exposure combined at a pedestrian level.

Focus at a pedestrian level is important because, for traffic-related pollutants, a significant fraction of overall exposure occurs within or close to the transit microenvironment (Hudda et al., 2012). The Aspect Ratio (the ratio between building height and street width) will affect air and noise pollutant levels. Air quality may vary between the leeward side footpath and the windward side footpath due to recirculating vortexes under particular meteorological conditions (Berkowicz et al., 1997). Further, research in London found that the location of an individual along the footpath has a significant impact on their exposure to traffic air pollutants (Kaur et al., 2007); effectively, the closer one is to a road's edge, the more exposed they are to harmful pollutants. This is because pollutants emitted from vehicles will disperse in an exponential fashion with 
increasing distance from the sources (McNabola and Gill, 2006). Similarly, in free field conditions, noise exposure declines with the square of the distance from the source. King et al. (2009) found that a dividing wall between road traffic and pedestrians reduced pedestrian exposure to both noise and air pollution. As such, one might expect that pedestrian exposure to noise and air pollution would decline as the segregation of human and road traffic increased.

While King et al. (2009) examined the effect of a dividing wall between a footpath and a road this paper examines the case for an elevated walkway in New York City called the High Line. The High Line allows pedestrians to not only be elevated from street level but also be positioned at a greater distance from the road, with various barriers, buildings and vegetation, between source and receiver (Fig. 1). It is thus hypothesized that pedestrian exposure to noise and air pollution on the High Line will be measurably reduced compared to levels found at street level, due to the greater segregation of road traffic and pedestrians.

\section{Methods}

Study area

The High Line, inspired by the Promenade Plantee in France, is an elevated urban greenway that has been open for pedestrian use since 2009. At the time of testing it stretched 1.45 miles in the heart of New York City from Gansevoort Street in the Meatpacking District to West 34th Street between 10th and 11th Avenues (after testing was completed, a new section opened). Pedestrians using the High Line are elevated at a greater distance away from road traffic and physically shielded from vehicles due to buildings, fences, barriers and vegetation.

\section{Measurement procedure}

Noise and air quality measurements were taken simultaneously by two study participants acting as pedestrians walking simultaneously along the High Line and along a footpath that runs parallel below. 35 pairs of noise and 61 pairs of air quality measurements were taken across three separate days of testing which included participants walking a combined 60 miles of the urban environment. Test Day 1 was a Friday (afternoon/evening), Test Day 2 was a Saturday (afternoon) and Test Day 3 was a Sunday (morning). Measurement periods were selected in an effort to capture the potential variation in exposure due to different traffic profiles during both peak and quiet hours. Fig. 2 presents typical weekly diurnal variation in traffic profiles for the major roads in the test area. Average meteorological conditions recorded during each test day are presented in Table 1. All test days were dry with no precipitation.

Noise measurements were acquired using two Brüel \& Kjær Type 2250 sound level meters. All noise levels reported are A-weighted decibel levels referenced to $20 \mu \mathrm{Pa}$. Two types of noise measurements were recorded: fixed spot measurements and mobile measurements. Spot measurements were ten minutes in duration, with microphones positioned on tripods at a height of $1.5 \mathrm{~m}$ relative to the ground surface and were taken in general accordance with ISO 1996-2 (ISO 1996-2, 1987). Spot measurements were taken at seven pairs of locations in the test area (Fig. 3), and repeated for a total of three samples per location, yielding 42 spot measurements in total. These positions included sections of the High Line that were directly open to the road traffic of 10th Avenue and sections that were shielded by either vegetation or buildings.

Mobile noise measurements were taken with sound level meters secured to backpacks in a similar fashion to Bennett et al. (2010) (Fig. 4). Mobile measurements were also taken in pairs along a number of 'trips': noise levels were recorded while walking from a start point (30th Street) on the High Line and footpath to a designated end point (14th Street). For each trip $L_{\mathrm{Aeq}}, L_{\mathrm{A} 10}$ and $L_{\mathrm{A} 90}$ values ${ }^{1}$ were logged along with the date and time of each measurement. Each instrument was calibrated prior to use.

Air quality measurements of $\mathrm{PM}_{2.5}$ were conducted using two TSI SidePak Personal Aerosol AM510 Monitors. This device is a laser photometer, which records aerosol mass concentration. The built in integrated pump allows for size-selective measurement by installing different inlet conditioners. The 2.5 micrometer inlet was used to acquire $\mathrm{PM}_{2.5}$ data. The monitor was worn by each study participant and set to $\log$ data every $10 \mathrm{~s}$ throughout a trip. Mobile measurements typically lasted twenty minutes in duration as two pedestrians walked at the same pace along the length of the High Line and the footpath below (along 10th Avenue). Analyses presented in this paper consider the overall average exposure for each trip.

\section{Results}

\section{Noise results}

Analyses are presented separately for the two sampling strategies. Fixed noise measurements are standard for environmental noise assessments and offer a reliable representation of the noise level at each measurement location. Mobile measurements provide high spatial resolution and, in this case, may offer a more appropriate representation of the noise a pedestrian is exposed to in the urban environment.

\footnotetext{
${ }^{1} L_{\mathrm{Aeq}}$ is the equivalent continuous A-weighted sound pressure level, $L_{\mathrm{A} 10}$ is the A-weighted sound pressure level that is exceeded for $10 \%$ of the time and $L_{\mathrm{A} 90}$ is the A-weighted sound pressure level that is exceeded for $90 \%$ of the time.
} 


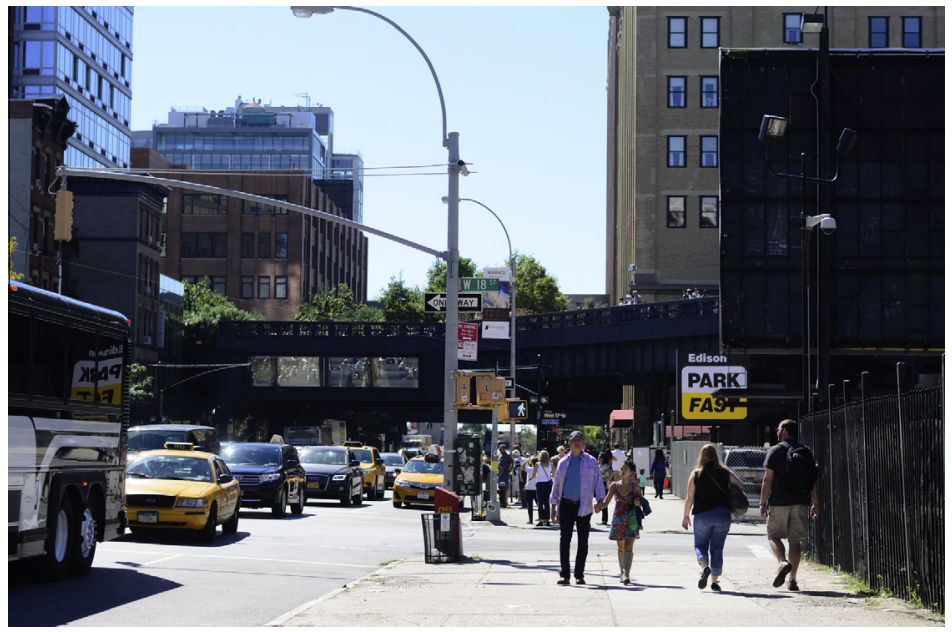

Fig. 1. Photo of the High Line, NYC. At this location, the High Line crosses 10th Avenue.

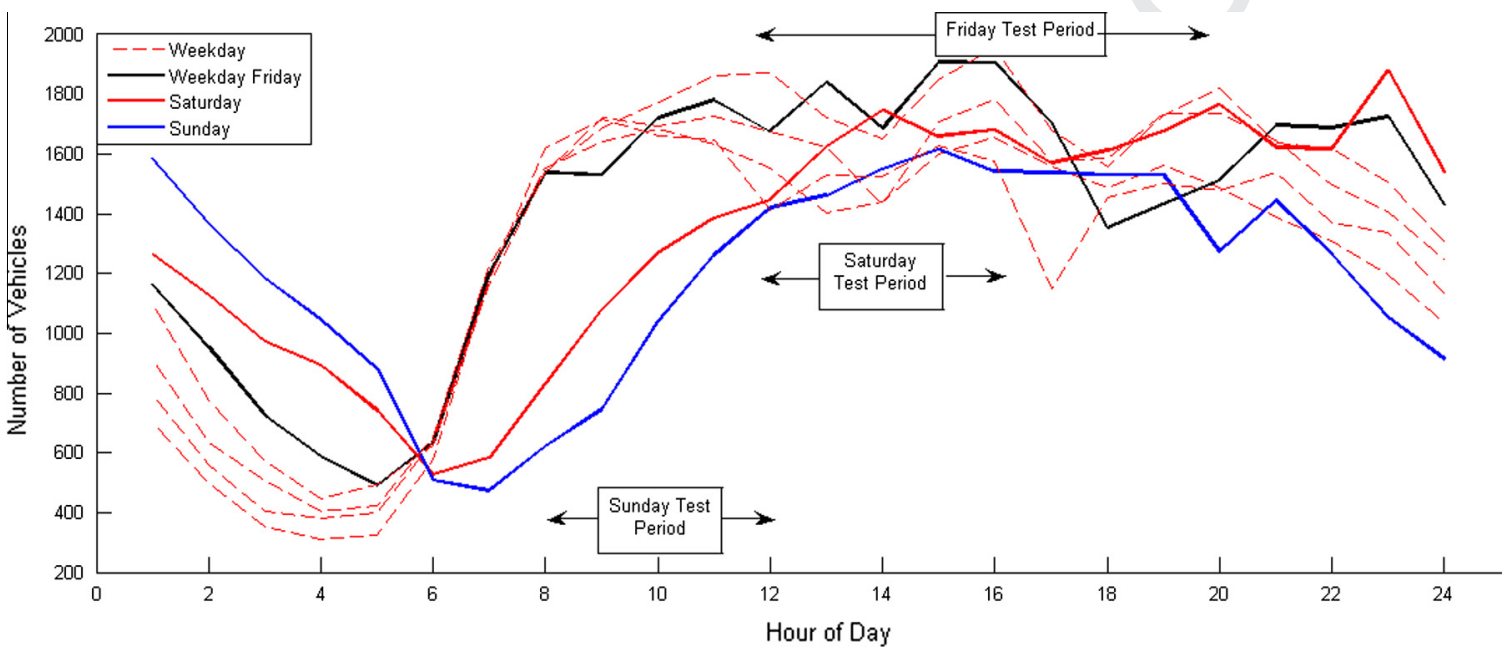

Fig. 2. Typical diurnal profiles for major road in test location. Profiles were calculated from average traffic volumes along 10th Avenue obtained from counters on 45th Street and 27th Street, spanning 17 days (City of New York, 2015).

Table 1

Average meteorological conditions recorded at a permanent weather station in Lincoln Square on Manhattan's West Side (Weather Underground, 2015).

\begin{tabular}{|c|c|c|c|c|c|c|}
\hline & Test day & & Average temperature & Average humidity & Precipitation & Average wind speed \\
\hline $9 / 26 / 2014$ & 1 & Friday & $68 \mathrm{~F}$ & 59 & $0.0 .0 \mathrm{in.}$ & $4 \mathrm{mph} / 1.79 \mathrm{~m} / \mathrm{s}(\mathrm{NE})$ \\
\hline $9 / 27 / 2014$ & 2 & Saturday & $72 \mathrm{~F}$ & 59 & $0.00 \mathrm{in.}$ & $3 \mathrm{mph} / 1.34 \mathrm{~m} / \mathrm{s}(\mathrm{NNW})$ \\
\hline $10 / 19 / 2014$ & 3 & Sunday & $50 \mathrm{~F}$ & 48 & $0.00 \mathrm{in.}$ & $8 \mathrm{mph} / 3.58 \mathrm{~m} / \mathrm{s}(\mathrm{NW})$ \\
\hline
\end{tabular}

Fixed noise measurement results

Fixed measurements were taken three times at 14 different measurement positions (seven pairs, see Fig. 3 ). Fig. 5 presents a comparison of the $L_{\mathrm{Aeq}}$ and $L_{\mathrm{A} 10}$ levels for each measurement pair. Table 2 reports the average difference between noise levels recorded at the footpath and the equivalent position on the High Line. The line of sight between the High Line and 10th Avenue (the major road below) is also reported.

Table 3 presents an overall statistical summary of these measurements. The average $L_{\text {Aeq }}$ level on the High Line was $67.3 \mathrm{~dB}(\mathrm{~A})$ while the average $L_{\mathrm{Aeq}}$ level along the footpath was $71.9 \mathrm{~dB}(\mathrm{~A}) . L_{\mathrm{A} 10}$ levels show a comparable difference between the High Line and the footpath; $68.1 \mathrm{~dB}(\mathrm{~A})$ and $74.6 \mathrm{~dB}(\mathrm{~A})$ respectively.

Results indicate that the average $L_{\text {Aeq }}$ level along the High Line is $4.6 \mathrm{~dB}(\mathrm{~A})$ lower than that experienced on the footpath below. A 95\% confidence interval of the difference reports that a minimum of $3.5 \mathrm{~dB}(\mathrm{~A})$ difference in $L_{\mathrm{Aeq}}$ levels should be 


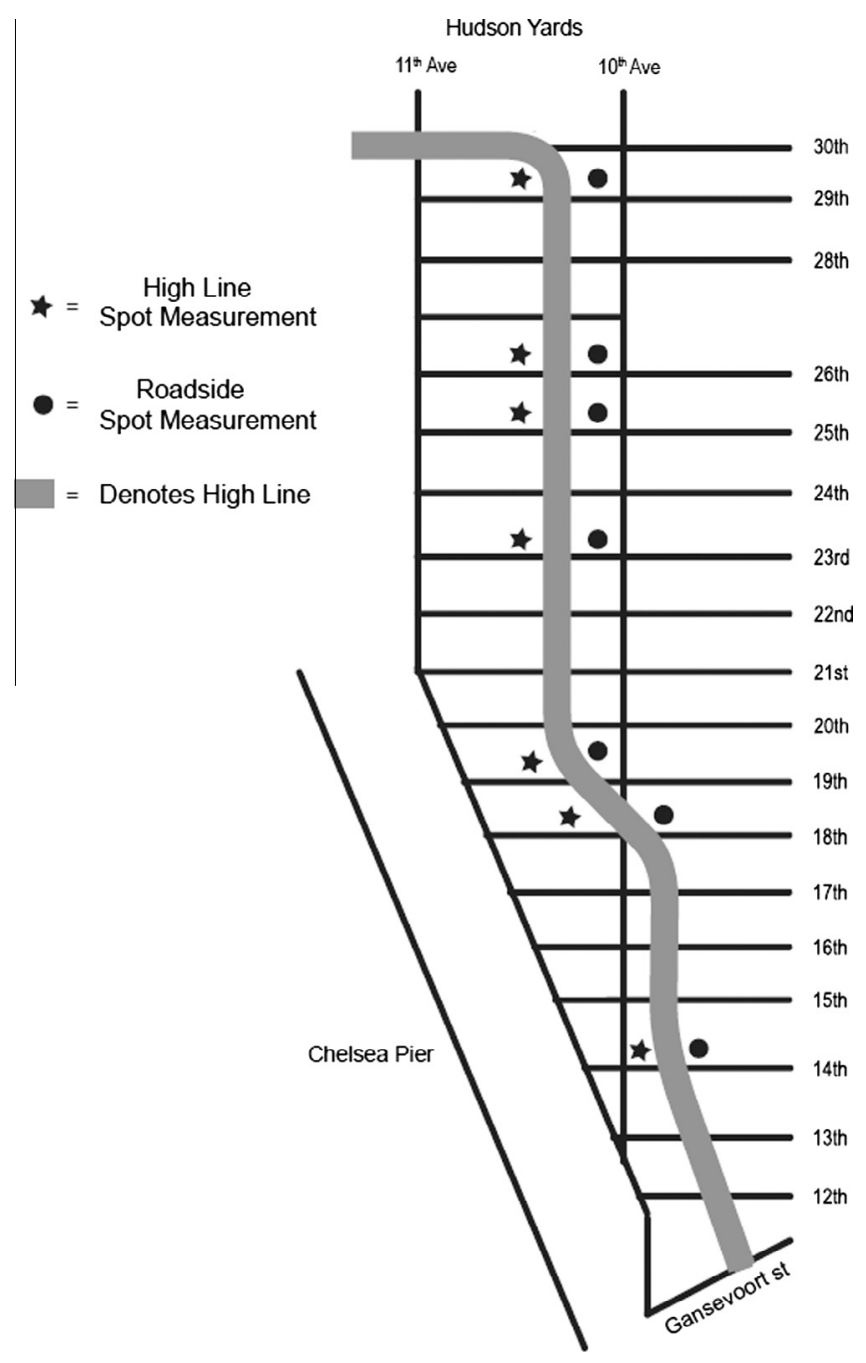

Fig. 3. Map of High Line with measurement locations.

expected. A two-sample $t$-test yielded a $p$-value of $4.4 \times 10^{-10}$ providing strong evidence to suggest the data are statistically significantly different (Sterne and Davey-Smith, 2001). ${ }^{2}$

Mobile noise measurement results

A total of 28 (14 pairs) mobile measurements were recorded. These measurements captured the complete acoustic nature of the urban environment i.e. the average noise exposure of a pedestrian walking from the start to the end of the measurement path. Fig. 6 reports the differences in overall $L_{\mathrm{Aeq}}$ and $L_{\mathrm{A} 10}$ levels between the High Line and the Footpath recorded using this measurement strategy.

Table 4 presents an overall statistical summary of these mobile measurements. Results indicate that the noise level along High Line is an average $3.9 \mathrm{~dB}(\mathrm{~A})$ lower than noise levels experienced along the footpath. A $p$-value of $9.4 \times 10^{-6}$ provides strong evidence to suggest the data are statistically significantly different.

The variance for measurements recorded along the High Line is higher than the Footpath. This was noted during testing. The soundscape of the High Line was a mixture of road traffic, construction activity, occasional street entertainers, a small café and the general hustle and bustle from patrons enjoying the High Line, whereas the sound along the footpath was dominated by road traffic noise.

Fig. 7 examines in more detail, the time-history of the mobile noise measurements. It presents the data logged on the High Line to the data logged on the footpath from one sample trip. Positive values for the difference between the two levels indicate consistent increased noise exposure for the pedestrian walking along the footpath compared to the High Line.

\footnotetext{
${ }^{2}$ Sterne and Davey-Smith (2001) offer that is reasonable to take a $p$-value of less than 0.001 as strong evidence against the null hypothesis.
} 


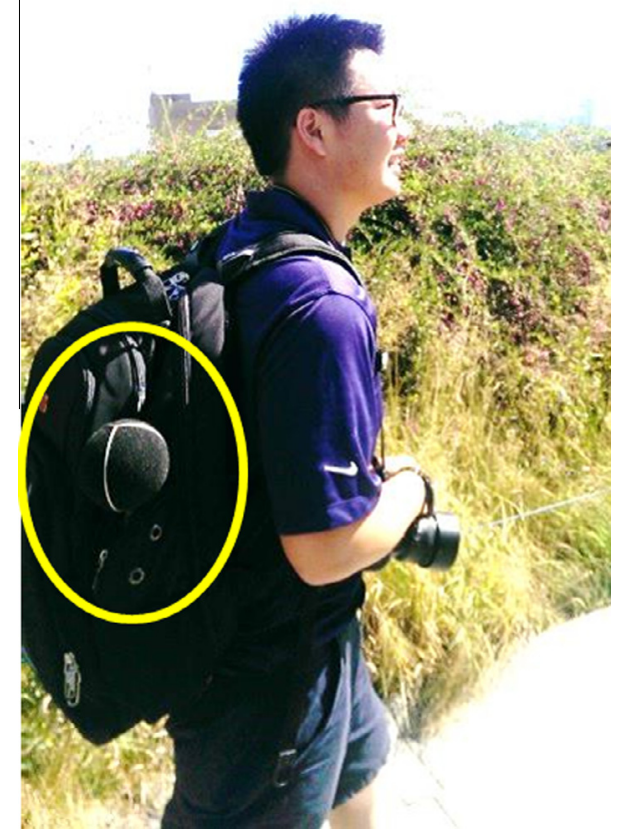

Fig. 4. Sound level meter positioned in side pocket of backpack with microphone exposed.

Air quality results

Using the same approach as mobile noise measurements, air quality measurements were recorded while participants walked from the start to the end of the measurement path. 61 pairs of measurements were recorded. Fig. 8 presents a summary of the recorded data while Table 5 presents an overall statistical summary of the data. The analysis suggests that the average $\mathrm{PM}_{2.5}$ concentration is approximately $7.7 \mu \mathrm{g} / \mathrm{m}^{3}$ greater on the footpath than the High Line. However, a large standard deviation in the data is noted and a 95\% confidence interval suggests that this difference may be as low as $2.8 \mu \mathrm{g} / \mathrm{m}^{3}$. The calculated a $p$-value of 0.001 provides evidence to suggest the data are statistically significantly different.

In previous studies, scholars have performed a regression analysis on air quality data recorded at a pedestrian level (McNabola et al., 2008; King et al., 2009). In keeping with this analysis approach, a regression analysis of this data was also performed (Fig. 9). A simple linear regression with a $R^{2}$ value of 0.67 is shown to fit the data. The relationship, with intercept at zero, suggests that pedestrian exposure on the footpath is approximately 1.37 times that on the High Line. The $R^{2}$ value of 0.67 indicates that approximately $33 \%$ of the variation is unexplained by the relative position of the High Line to the footpath. However, if a non-zero intercept is applied (Fig. 10) the exposure on the footpath is reduced from 1.37 times to 1.15 times that of the High Line with an $R^{2}$ value of 0.70 .

Fig. 11 examines in more detail, the time-history of the air quality measurements. It presents the $\mathrm{PM}_{2.5}$ concentration data logged on the High and the footpath for one sample test. Consistent positive values when plotting the difference indicates increased concentrations of $\mathrm{PM}_{2.5}$ when the pedestrian walks along the footpath compared to the High Line.

\section{Air-noise pollution reduction index}

Several studies have combined air and noise pollution data into some form of a single number index (Fung and Lee, 2011; Silva and Mendes, 2012). For the current study, the air-noise pollution reduction index $\left(\mathrm{ANP}_{\mathrm{r}}\right)$ can be used to quantify the level of reduction in environmental pollutants at a pedestrian level (King et al., 2009). The $\mathrm{ANP}_{\mathrm{r}}$ is a simple index that may be used for urban planning and informative purposes. The $\mathrm{ANP}_{\mathrm{r}}$ is calculated by finding the average percentage reduction of both pollutants and calculating the mean of the two. The overall results for noise and air pollution along with percentage reductions are presented in Table 6. The results indicate that the High Line induces an $\mathrm{ANP}_{\mathrm{r}}$ of $36.5 \%$ i.e. the average reduction in air and noise pollution along the High Line compared to the footpath below is $36.5 \%$.

\section{Discussion}

This study offers an evaluation of pedestrian exposure to noise and particulate matter in Manhattan along an elevated walkway compared to a street level footpath. Results suggest that this elevated walkway has had a positive environmental impact for its users in terms of reduced pedestrian exposure to both noise and air pollution. However, these pollutants can be 

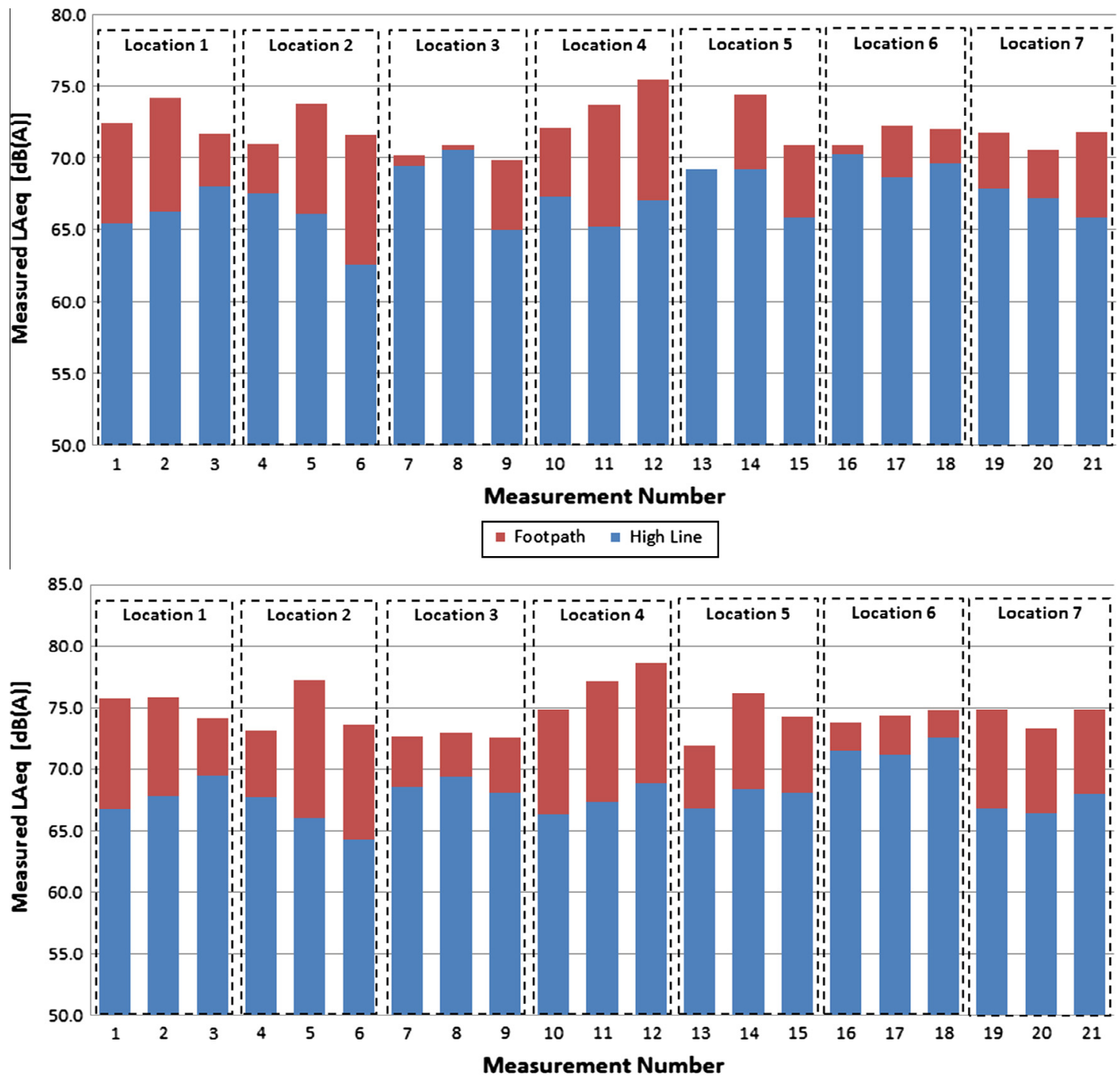

E Footpath High Line

Fig. 5. $L_{\mathrm{Aeq}}$ and $L_{\mathrm{A} 10}$ measurement results for fixed spot measurements.

Table 2

Average $L_{\mathrm{Aeq}}$ and $L_{\mathrm{A} 10}$ difference for fixed spot measurements.

\begin{tabular}{|c|c|c|c|}
\hline $\begin{array}{l}\text { Approximate measurement } \\
\text { location }\end{array}$ & View & $\begin{array}{l}\text { Average difference } L_{\text {Aeq }} \\
\mathrm{dB}(\mathrm{A})\end{array}$ & $\begin{array}{l}\text { Average difference } L_{\mathrm{A} 10} \\
\mathrm{~dB}(\mathrm{~A})\end{array}$ \\
\hline Location $1-29$ th St & No line of sight to 10th Avenue & 6.2 & 7.2 \\
\hline Location $2-26$ th St & Partial line of sight to 10 th Avenue & 6.7 & 8.7 \\
\hline Location $3-25$ th St & $\begin{array}{l}\text { Partial line of sight to 10th Avenue (blocked only by } \\
\text { vegetation) }\end{array}$ & 2.0 & 4.1 \\
\hline Location $4-23$ th St & No line of sight to 10th Avenue & 7.3 & 9.3 \\
\hline Location 5 - 19th St & Clear line of sight to 10 th Avenue & 3.3 & 6.4 \\
\hline Location 6 - 18th St & Clear line of sight to 10 th Avenue & 2.2 & 2.6 \\
\hline
\end{tabular}

influenced by various local factors such as meteorological effects and street geometry. Further investigation would be required to confirm if these results may be extrapolated to elevated walkways at different sites, or indeed for varying meteorological conditions. 
Table 3

Statistical analysis of difference for fixed spot measurements.

\begin{tabular}{|c|c|c|c|c|c|c|c|c|c|c|c|}
\hline & & \multicolumn{5}{|c|}{ Descriptive statistics } & \multicolumn{5}{|c|}{$t$-test for Difference of Means } \\
\hline & & \multirow[t]{2}{*}{$\begin{array}{l}\text { Average } \\
L_{\text {Aeq }}\end{array}$} & \multirow[t]{2}{*}{$\begin{array}{l}\text { Standard } \\
\text { deviation }\end{array}$} & \multirow[t]{2}{*}{ Max. } & \multirow[t]{2}{*}{ Min. } & \multirow[t]{2}{*}{ Count } & \multirow[t]{2}{*}{ Mean difference } & \multirow[t]{2}{*}{$t$} & \multirow[t]{2}{*}{$p$-value } & \multicolumn{2}{|c|}{$\begin{array}{l}\text { 95\% confidence } \\
\text { interval of the } \\
\text { difference }\end{array}$} \\
\hline & & & & & & & & & & Lower & Upper \\
\hline Spot tests & High Line & 67.3 & 2.0 & 70.5 & 62.5 & 21 & 4.6 & 8.08 & $4.4 \mathrm{e}-10$ & 3.5 & 5.7 \\
\hline Summary & Footpath & 71.9 & 1.6 & 75.5 & 68.9 & 21 & & & & & \\
\hline
\end{tabular}
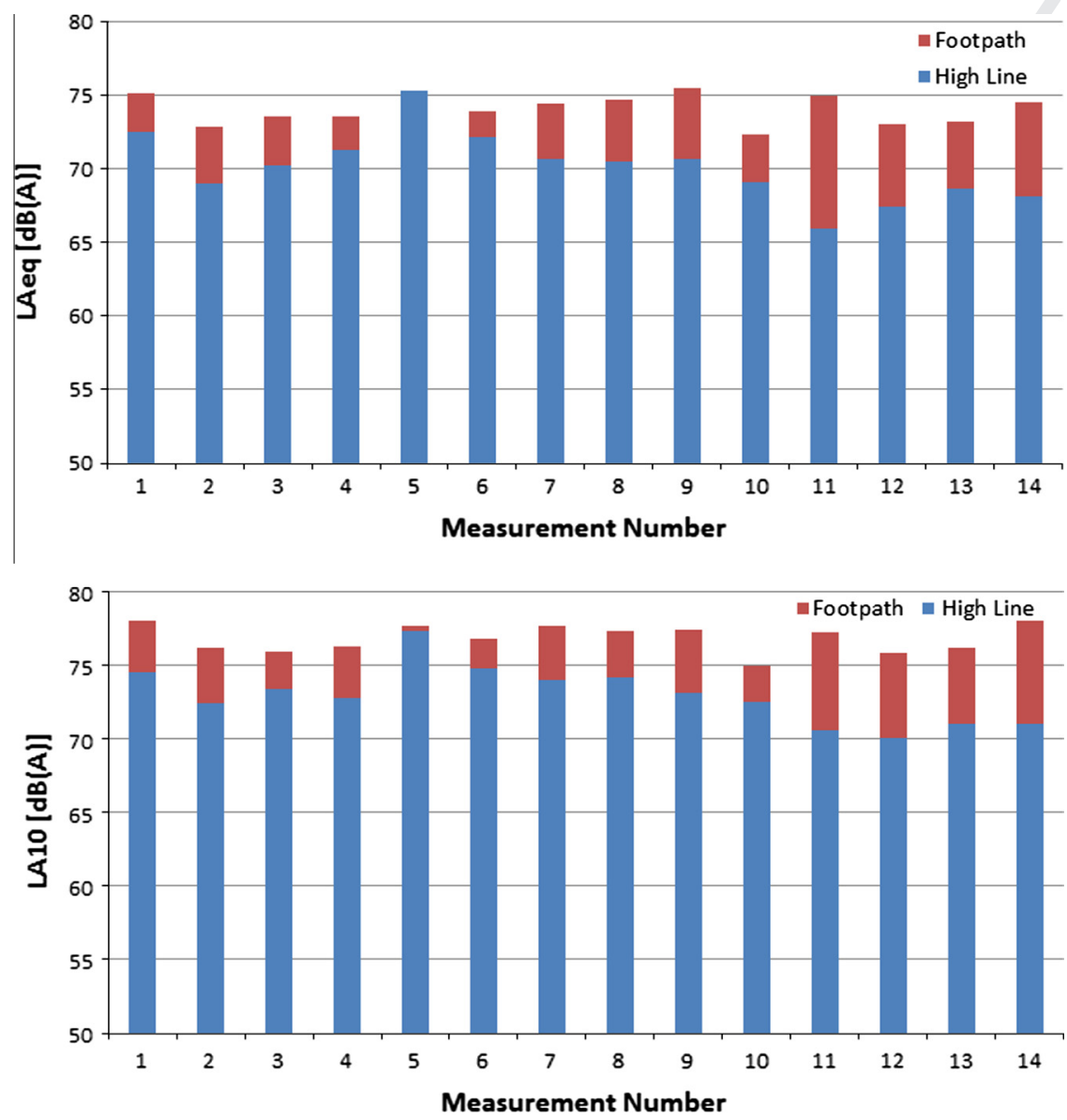

Fig. 6. $L_{\mathrm{Aeq}}$ and $L_{\mathrm{A} 10}$ measurement results for mobile noise measurements.

Table 4

Statistical analysis of difference for mobile noise measurements.

\begin{tabular}{|c|c|c|c|c|c|c|c|c|c|c|c|}
\hline & & \multicolumn{5}{|c|}{ Descriptive statistics } & \multicolumn{5}{|c|}{$t$-test for Difference of Means } \\
\hline & & \multirow[t]{2}{*}{$\begin{array}{l}\text { Average } \\
L_{\text {Aeq }}\end{array}$} & \multirow[t]{2}{*}{$\begin{array}{l}\text { Standard } \\
\text { deviation }\end{array}$} & \multirow[t]{2}{*}{ Max. } & \multirow[t]{2}{*}{ Min. } & \multirow[t]{2}{*}{$\overline{\text { Count }}$} & \multirow[t]{2}{*}{ Mean difference } & \multirow[t]{2}{*}{$T$} & \multirow[t]{2}{*}{$p$-value } & \multicolumn{2}{|c|}{$\begin{array}{l}\text { 95\% confidence } \\
\text { interval of the } \\
\text { difference }\end{array}$} \\
\hline & & & & & & & & & & Lower & Upper \\
\hline Mobile tests & High Line & 70.1 & 2.35 & 75.6 & 65.9 & 14 & 3.9 & 6.5 & $9.4 \mathrm{e}-6$ & 2.50 & 5.30 \\
\hline Summary & Footpath & 74.0 & 0.99 & 75.46 & 72.26 & 14 & & & & & \\
\hline
\end{tabular}



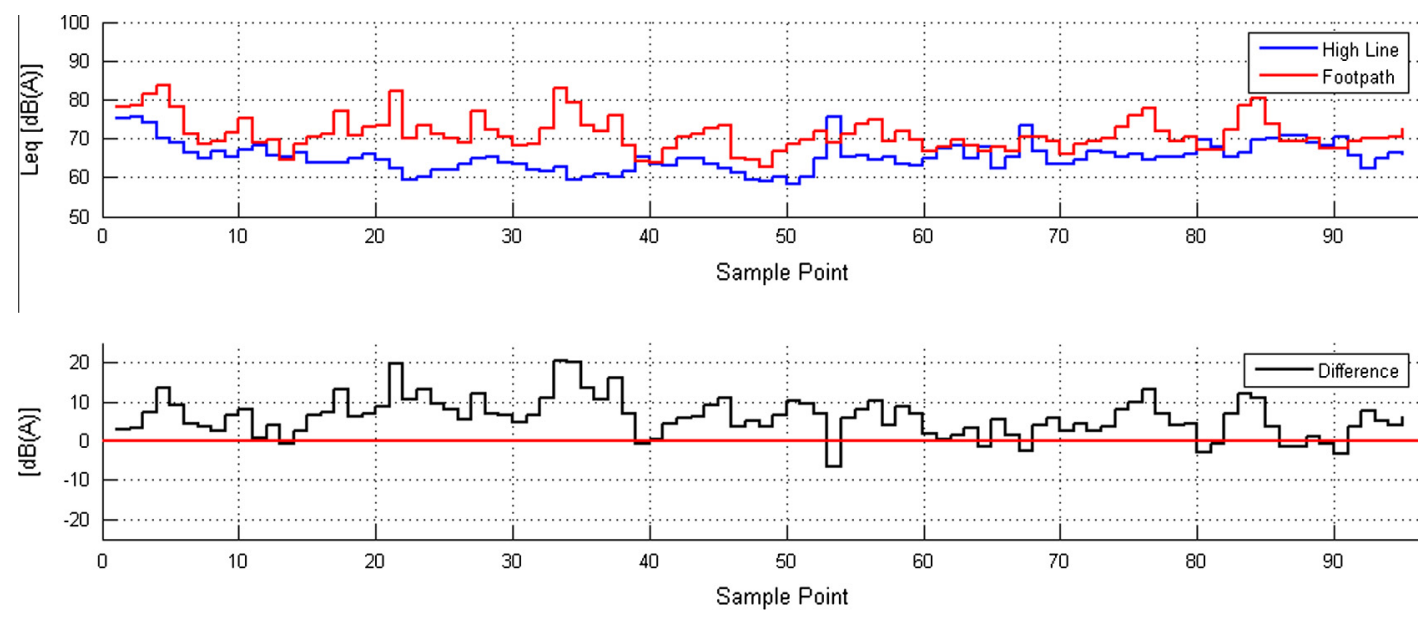

Fig. 7. Noise measurement data for selected trip.

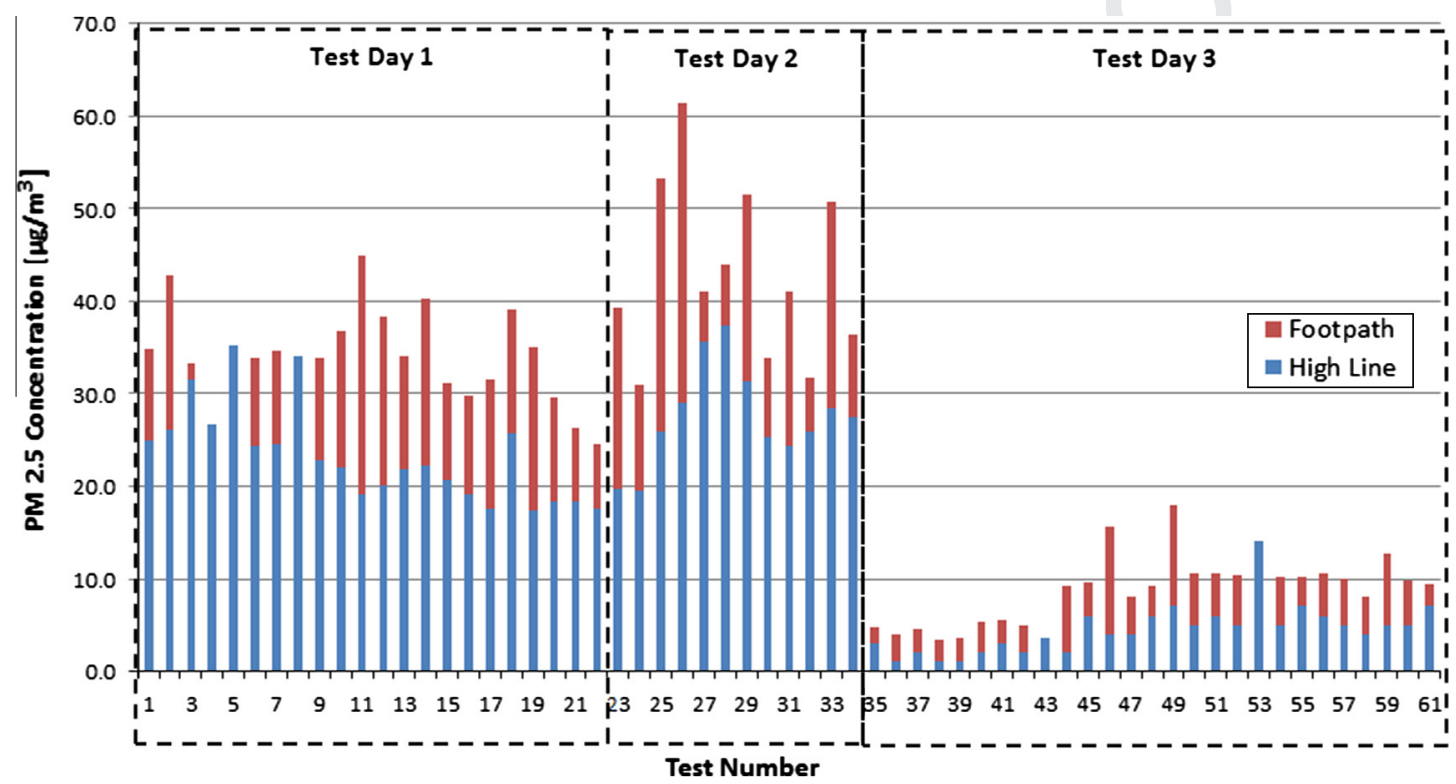

Fig. 8. Air quality measurement results for measurement pairs.

Table 5

Statistical analysis of difference for air quality measurements.

\begin{tabular}{|c|c|c|c|c|c|c|c|c|c|c|c|}
\hline & & \multicolumn{5}{|l|}{ Descriptive statistics } & \multicolumn{5}{|c|}{$t$-test for Difference of Means } \\
\hline & & \multirow[t]{2}{*}{$\begin{array}{l}\text { Average } \\
\mathrm{PM}_{2.5} \text { concentration }\end{array}$} & \multirow[t]{2}{*}{$\begin{array}{l}\text { Standard } \\
\text { deviation }\end{array}$} & \multirow[t]{2}{*}{ Max. } & \multirow[t]{2}{*}{ Min. } & \multirow[t]{2}{*}{ Count } & \multirow[t]{2}{*}{ Mean Difference } & \multirow[t]{2}{*}{$t$} & \multirow[t]{2}{*}{$p$-value } & \multicolumn{2}{|c|}{$\begin{array}{l}95 \% \text { confidence } \\
\text { interval of the } \\
\text { difference }\end{array}$} \\
\hline & & & & & & & & & & Lower & Upper \\
\hline Air quality tests & High Line & 16.2 & 11.4 & 37.4 & 1.0 & 61 & 7.7 & 3.12 & 0.001 & 2.80 & 12.6 \\
\hline Summary & Footpath & 23.9 & 15.6 & 61.3 & 1.1 & 61 & & & & & \\
\hline
\end{tabular}

Uncertainties and influence of external factors

Levy and Hanna (2011) note that as New York City is a densely populated urban area with numerous street canyons and complex terrain, it would have significant local contributions and near-roadway effects in particulate matter concentrations, some of which would be short in duration while others would influence long-term average concentrations. These local 


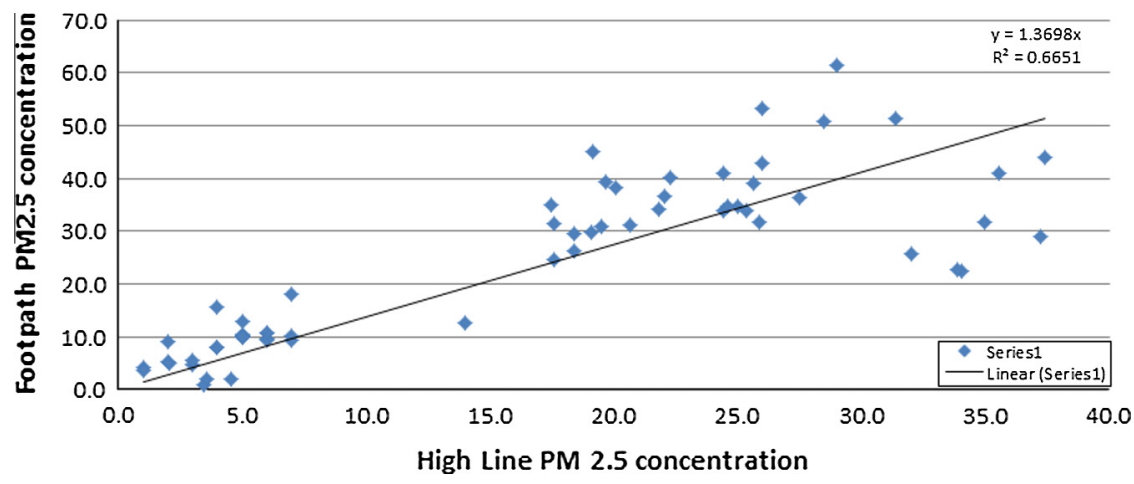

Fig. 9. Regression analysis of air quality data with zero intercept.

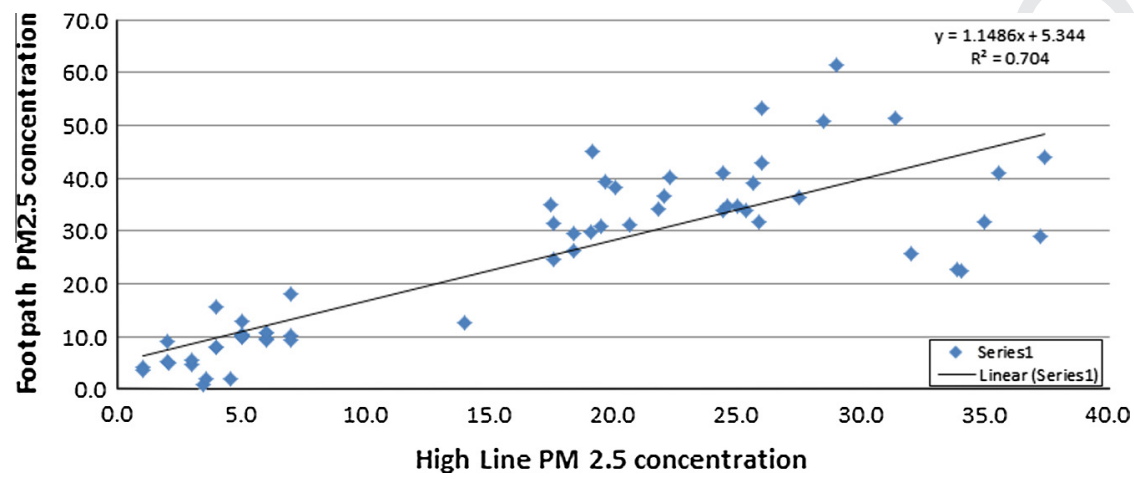

Fig. 10. Regression analysis of air quality data with non-zero intercept.
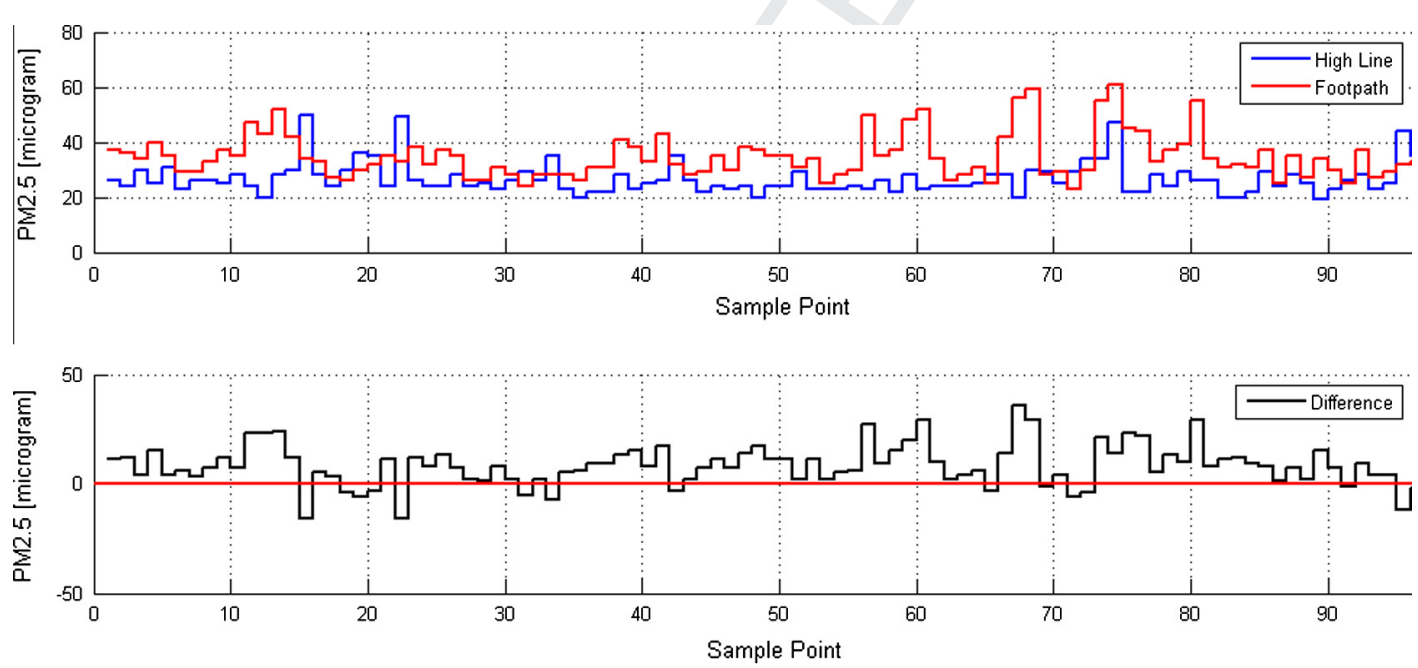

Fig. 11. Air quality measurement data for sample trip.

Table 6

Summary of overall average decrease in pollutant levels. Note: noise levels have been converted to Paschal to allow the computation of a percentage reduction.

\begin{tabular}{lllll}
\hline & High Line & Footpath & Decrease & \% Decrease \\
\hline Noise $(\mathrm{Pa})$ & 0.04635 & 0.07871 & 0.03236 & 41 \\
$\mathrm{PM}_{2.5}$ concentration $\left(\mu \mathrm{g} / \mathrm{m}^{3}\right)$ & 16.2 & 23.9 & 7.7 & 32
\end{tabular}


effects may have influenced the current study and have led to some uncertainty in results. For example, background levels of $\mathrm{PM}_{2.5}$ may have influenced results but it is not possible to fully quantify the effect background levels may have had. The concept of background concentrations of particulate matter can be elusive, given that $\mathrm{PM}_{2.5}$ may have contributions from nonanthropogenic background, intercontinental transport, regional transport, and the urban and neighbourhood scale as well as background concentrations varying over time as a function of gross wind direction and speed, mixing depth, sunlight, and other factors (Levy and Hanna, 2011).

Other uncertainties arise when atmospheric conditions are considered. Atmospheric conditions such as temperature, wind patterns and other local meteorological effects can have an effect on noise propagation, but effects may be more significant in considerations of $\mathrm{PM}_{2.5}$ concentrations. Street geometry, wind speed and wind direction may lead to the development of a street canyon vortex. Formation of a vortex within a street canyon may occur at an ambient wind velocity above $1.5-2.0 \mathrm{~m} / \mathrm{s}$ (Berkowicz et al., 1997), the formation of a stable vortex is much less likely at lower wind speeds, i.e. winds speed below $2 \mathrm{~m} / \mathrm{s}$ (Vardoulakis et al., 2005). In the presence of a vortex the local airflow at street level is in the opposite direction to that at roof level, resulting in higher concentrations of pollutants on the leeward side of the street compared with the windward side (Manning et al., 2000). In the case of the High Line the street geometry changes from start to end, so it is possible that, under certain scenarios, there may be pollutant hotspots along the walkway due to varying local effects. This study did not attempt to quantify the effect different local conditions might have and further testing, including detailed CFD modelling, would be required to assess these effects in detail.

Results may also have been impacted by construction activity in the test area. There were a number of active construction sites in operation during testing. Hudson Yards, a large scale construction site nearby, is proposed to be completed around the end of 2018 and will include a park of its own in its centre. Previous scholars have reported $\mathrm{PM}_{2.5}$ levels as high as $101.91 \mu \mathrm{g} / \mathrm{m}^{3}$ within the surrounding construction perimeter (Araujo et al., 2014). Such construction activity is likely to have impacted the measured pollutant levels. In the future, when construction is complete, further testing may yield a more comprehensive comparison of air quality and noise levels between the High Line and the footpath. It may be that the actual benefit of the High Line may be greater than reported in this study.

\section{Considerations for urban planners}

Creating quiet places and enhancing possibilities for quiet recreation in urban environments can also have a positive effect on the quality of life in a city (Booi and van den Berg, 2012). The concept of quiet urban areas has been extended to the development of appropriate urban soundscapes. Soundscapes have been identified as a means of approaching the preservation and maintenance of locations that have, or may require, acoustical consideration to enhance the quality of life (Memoli and Licitra, 2013). For the current case, the mean difference in noise exposure between the High Line and the footpath was $4.6 \mathrm{~dB}(\mathrm{~A})$. This is a perceptible difference, but the actual soundscape was also quite different in both cases. The dominant source of noise experienced on the footpath was road traffic, whereas along the High Line it varied between park activities and the general hum of the city. So, while we can point to a measured difference of $4.6 \mathrm{~dB}(\mathrm{~A})$, the actual improvement in terms of sound quality is likely to be greater.

Areas of reduced particulate matter concentration would have clear benefits for urban pedestrians and the benefit would be even greater for residents who wish to exercise in the city. While it would be more efficient to tackle the problems at source, urban planners can use innovative strategies to better protect city residents through the dispersion of harmful pollutants. McNabola et al. (2008) identified that a boundary wall between roadways and pedestrians will reduce health effects from air pollutants. The current study suggests that an elevated walkway could offer similar benefits. This is important as planning authorities consider various urban renewal projects, including 'parks in the sky'. For example, developments similar to the High Line have been considered in Philadelphia, Chicago, Rotterdam and Hong Kong (Taylor, 2010). If urban planners could provide pedestrians with alternative routes providing greater segregation of pollution sources, pedestrians could then actively reduce their personal exposure to particulate matter and noise by choosing to incorporate such a path in their route selection.

\section{A combined air and noise pollution index}

It is noted that the underlying mechanisms behind air and noise pollution reductions are different. The primary mechanisms behind the reduction in noise levels were due to pedestrians being situated at an increased distance from source and the impact of barriers (in the form of buildings, walls or vegetation). Reductions in the air pollution exposure concentrations are likely due to increased distance from the source (resulting in increased dispersion/dilution of pollution concentrations) but also reflect the influence of buildings diverting the natural flow of air away from pedestrians using the High Line i.e. urban street canyons. These attenuation effects have been modelled for both pollutants separately in an urban environment (Pilla and Broderick, 2015; King and Rice, 2009). It is possible that future studies may combine such models using a combined air-noise pollution index. This would have considerable potential for use in aiding the decision making of urban planners in a variety of urban contexts.

In the current case we use the simple air-noise pollution index to quantify the level of combined pollutant reduction at the pedestrian level. Using this index, our results suggest an average reduction of 36.5\% in pollutants along the High Line compared to the footpath below. In their introduction of this index, King et al. (2009) note that the index may be regarded 
as a preliminary tool for informative purposes and undoubtedly needs to be subjected to more rigorous empirical investigation. A single number index such as this is useful to quantify the impact a planning measure might have on multiple pollutants and may be used to engage a non-expert public on important planning issues. Instead of a simple arithmetic mean, future studies may include weighting factors to reflect situations where one pollutant type might be considered more important than another based on, for example, public perception or proliferation of associated health effects.

\section{Mobile noise measurements}

This study also demonstrates the potential for mobile measurements in environmental noise assessments. This is important in the context of combined air and noise assessments as air quality assessments often include both mobile and fixed stations, whereas mobile noise measurements are rarely used in environmental noise assessments. In this case the average noise levels on the footpath recorded using the fixed and mobile measurements were within $2.1 \mathrm{~dB}(\mathrm{~A})$. There was a slightly higher variation in measurements recorded on the High Line; mobile measurements yielded an average $L_{\mathrm{Aeq}}$ of $70.1 \mathrm{~dB}(\mathrm{~A})$ compared to $67.3 \mathrm{~dB}(\mathrm{~A})$ using fixed measurements. This is due to the sound level meter being in the vicinity of extraneous noise sources (occasional street entertainers, patrons at a small café, etc.) at various points along the route during mobile measurements and is reflected in the degree of variance reported. While undertaking fixed measurements an effort was made to follow general good practice, i.e. we tried to position the meter to minimise the impact of these local sources. However, overall the relative difference in fixed measurements compared to mobile measurements was within $1 \mathrm{~dB}(\mathrm{~A})$.

\section{Conclusion}

Our results show that the High Line has had a positive environmental impact for its users in terms of reduced pedestrian exposure to both noise and air pollution. In order to quantify the overall impact, results expressed through the air-noise pollution reduction index indicate that the average reduction in pollution along the High Line is approximately $37 \%$ less when compared to the footpath below. This supports the previous work of McNabola et al. (2008) and King et al. (2009) who suggest that greater segregation of pedestrian and road traffic has the potential to considerably reduce pedestrian exposure to harmful pollutants. The High Line has served not only to improve the aesthetics of the city as a public park but also to promote the health of its inhabitants.

\section{Acknowledgements}

The authors would like to acknowledge funding received from the University of Hartford under the Greenberg Junior Faculty Grant 2014-2015.

\section{References}

Araujo, I.P.S., Costa, D.B., de Moraes, R.J.B., 2014. Identification and characterization of particulate matter concentrations at construction jobsites. J. Sustain. 6 (11), 7666-7688.

Allen, R.W., Davies, H., Cohen, M.A., Mallach, G., Kaufman, J.D., Adar, S.D., 2009. The spatial relationship between traffic-generated air pollution and noise in 2 US cities. Environ. Res. 109, 334-342.

Babisch, W., Beule, B., Schust, M., Kersten, N., Ising, H., 2005. Traffic noise and risk of myocardial infarction. Epidemiology 16 (1).

Bennett, G., King, E.A., Curn, J., Cahill, V., Rice, H.J., 2010. Environmental noise mapping using measurements in transit. In: Proceedings of ISMA 2010, Leuven, Brussels.

Berkowicz, R., Hertel, O., Larsen, S.E., Sorensen, N.N., Nielsen, M., 1997. Modelling Traffic Pollution in Streets. NERI, Roskilde, Denmark.

Booi, H., van den Berg, F., 2012. Quiet areas and the need for quietness in Amsterdam. Int. J. Environ. Res. Public Health 9 (4), $1030-1050$.

Boogaard, H., Borgman, F., Kamming, J., Hoek, G., 2009. Exposure to ultrafine and fine particles and noise during cycling and driving in 11 Dutch cities. Atmos. Environ. 43, 4234-4242.

City of New York, 2013. Mayor's Management Report, Fiscal 2013. New York Mayor's Office of Operations' Performance Management Team.

City of New York, 2015, NYC Open Data Portal. <https://data.cityofnewyork.us/NYC-BigApps/Traffic-Volume-Counts-2012-2013-/p424-amsu> (website data accessed September 1st 2015).

Cohen, A.J., Anderson, H.R., Ostra, B., Dev, Pandey.K., Krzyzanowski, M., Kunzli, N., Guschmidt, K., Pope, A., Romieu, I., Samet, J.M., Smith, K., 2005. The global burden of disease due to outdoor air pollution. J. Toxicol. Environ. Health, Part A 68, 1-7.

Committee on Technology for a Quieter America, 2010. Technology for a Quieter America, National Academy of Engineering.

Dockery, D.W., 2011. Epidemiological evidence of cardiovascular effects of particulate air pollution. Environ. Health Perspect. 109 (S4), $483-489$.

Fung, Y.W., Lee, W.L., 2011. Identifying a common parameter for assessing the impact of traffic-induced noise and air pollutions on residential premises in Hong Kong. Habitat Int. 35.

Gordon, T., Reibman, J., 2000. Cardiovascular toxicity of inhaled ambient particulate matter. Toxicol. Sci. 56 (1), 2-4.

Hammer, M.S., Swinburn, T.K., Neitzel, R.L., 2014. Environmental noise pollution in the United States: developing an effective public health response. Environ. Health Perspect. 122 (2).

Hudda, N., Eckel, S.P., Knibbs, L.D., Sioutas, C., Delfino, R.J., Fruin, S.A., 2012. Linking in-vehicle ultrafine particle exposures to on-road concentrations. Atmos. Environ. 59, 578-586.

International Organization for Standardization, 1996. ISO 9613-2 (1996) Acoustics - Attenuation of Sound during Propagation Outdoors - Part 2: General Method of Calculation.

Kaur, S., Nieuwenhuijsen, M.J., Colvile, R.N., 2007. Fine particulate matter and carbon monoxide exposure concentrations in urban street transport microenvironments. Atmos. Environ. 41 (23), 4781-4810.

King, E.A., Murphy, E., McNabola, A., 2009. Reducing pedestrian exposure to environmental pollutants: a combined noise exposure and air quality analysis approach. Transport. Res. Part D: Transport Environ. 14 (5), 309-316. 
King, E.A., Murphy, E., Rice, H.J., 2011. Evaluating the impact on noise levels of a ban on private cars in Dublin city centre, Ireland. Transport. Res. Part D 16 (7), 532-539.

King, E.A., Rice, H.J., 2009. The development of a practical framework for strategic noise mapping. Appl. Acoust. 70 (8), 1116-1127.

Levy, J., Hanna, S.R., 2011. Spatial and temporal variability in urban fine particulate matter concentrations. Environ. Pollut. 159, $2009-2015$.

Manning, A.J., Nicholson, K.J., Middleton, D.R., Rafferty, S.C., 2000. Field study of wind and traffic to test a street canyon pollution model. Environ. Monit. Assess. 60, 283-313.

Memoli, G., Licitra, G., 2013. From noise mapping to annoyance mapping: a soundscape approach. In: Licitra, G. (Ed.), Noise Mapping in the EU: Models and Procedures. CRC Press, Florida, pp. 371-391.

McNabola, A., Gill, L.W., 2006. An experimental and numerical investigation of idling traffic. In: Proceedings of the Second IASTED International Conference on Environmental Modeling and Simulation, US Virgin Islands, pp. 37-42.

McNabola, A., Broderick, B., Gill, L.W., 2008. Reduced exposure to air pollution on the boardwalk in Dublin, Ireland. Measurement and prediction. Environ. Int. 34 (1), 86-93.

Murphy, E., King, E.A., 2014. Environmental Noise Pollution: Noise Mapping, Public Health and Policy. Elsevier, ISBN 9780124115958.

Nawrot, T.S., Perez, Künzli.L., Munters, E., Nemery, B., 2011. Public health importance of triggers of myocardial infarction: a comparative risk assessment. The Lancet 377 (9767), 732-740.

New York City Department of Environmental Protection, 2014. A Guide to New York City’s Noise Code: Understanding the Most Common Sources of Noise in the City. Bureau of Environmental Compliance.

New York City Department of Health and Mental Hygiene, 2011, The New York Coty Community Air Survey, Results from Year One Monitoring 2008-2009.

New York City Department of Health and Mental Hygiene, 2013. New York City trends in air pollution and its health consequences. NYC Health Report, September 262013.

Pierson, W.E., Covert, D.S., Koenig, J.Q., 1986. Review: implications of air pollution effects on athletic performance. Atmos. Environ. (1967) 20 (10), 20332038.

Pilla, F., 2014. Particulate matter (PM10 and PM2.5). Encyclopedia of Transportation, Social Science and Policy. SAGE Publications Inc..

Pilla, F., Broderick, B., 2015. A GIS model for personal exposure to PM10 for Dublin commuters. Sustain. Cities Soc. 15, 1-10.

Ross, Z., Kheirbek, I., Clougherty, J.E., Ito, K., Matte, T., Markowitz, S., Eisl, H., 2012. Noise, air pollutants and traffic: continuous measurement and correlation at a high-traffic location in New York City. Environ. Res. 111 (8), 1054-1063.

Schwela, D., Zali, O., 1999. Urban Traffic Pollution. Routledge, London, United Kingdom.

Sharman, J.E., Cockcroft, J.R., Coombes, J.S., 2004. Cardiovascular implications of exposure to traffic air pollution during exercise. QJM 97 (10), $637-643$.

Silva, L.T., Mendes, J.F.G., 2012. City noise-air: an environmental quality index for cities. Sustain. Cities Soc. 4, 1-11.

Skylar, E., Barowitz, J., 2005. New York City PR-484-05. Press Release: Mayor Bloomberg Signs Legislation Overhauling Noise Code, December 29, 2005.

Stableford D., 2014. Smogathon: Beijing Marathon held despite "hazardous" air quality. Yahoo News, October 20. Available online at <http://news. yahoo.com/beijing-marathon-smog-controversy-155331342.html> (accessed 12 November 2014).

Sterne, J.A.C., Davey-Smith, G., 2001. Sifting the evidence - what's wrong with significance tests? Br. Med. J. 322, $226-231$.

Swinburn, T.K, Hammer, M.S., Neitzel, R.L., 2015. Valuing quiet - an economic assessment of U.S. environmental noise as a cardiovascular health hazard. Am. J. Prevent. Med. (in press).

Taylor, K., 2010. After High Line's Success, Other Cities Look Up. New York Times (July 14th).

United Nations, 2014. World Urbanization Prospects: The 2014 Revision, Highlights (ST/ESA/SER.A/352). United National Department of Economic and Social Affairs, Population Division.

Vardoulakis, S., Gonzalez-Flesca, N., Fisher, B.E.A., Pericleous, K., 2005. Spatial variability of air pollution in the vicinity of a permanent monitoring station in central Paris. Atmos. Environ. 39, 2725-2736.

Vlachokostas, Ch., Achillas, Ch., Michailidou, A.V., Moussiopoulos, N., 2012. Measuring combined exposure to environmental pressures in urban areas: an air quality and noise pollution assessment approach. Environ. Int. 39, 8-18.

Vlachokostas, C., Banias, G., Athanasiadis, A., Achillas, C., Akylas, V., Moussiopoulos, N., 2014. Cense: a tool to assess combined exposure to environmental health stressors in urban areas. Environ. Int. 63, 1-10.

Weather Underground, Weather History for KNYC station, 2015. Available at <http://www.wunderground.com/history/airport/KNYC> (accessed September 3rd 2015).

Zanobetti, A., Schwartz, J., 2009. The effect of fine and coarse particulate air pollution on mortality: a national analysis. Environ. Health Perspect. 117 (6), 898-903. 